Stefanie Keymel

Christoph Kalka

Tienush Rassaf

Yerem Yeghiazarians

Malte Kelm

Christian Heiss

\section{Impaired endothelial progenitor cell function predicts age-dependent carotid intimal thickening}

Abstract Objectives We investigated whether qualitative or quantitative alterations of the endothelial progenitor cell (EPC) pool predict age-related structural vessel wall changes. Background We have previously shown that age-related endothelial dysfunction is accompanied by qualitative rather than quantitative changes of EPCs. Animal studies suggest that impaired EPC functions lead to accelerated arterial intimal thickening. Methods Intima-media thickness (IMT) was measured in the common carotid artery in our previously published groups of younger $(25 \pm 1$ years, $n=20)$ and older $(61 \pm 2$ years, $n=20)$ healthy non-smoking volunteers without arterial hypertension, hypercholesterolemia, and diabetes mellitus. Endothelial progenitor cells (EPCs, $\mathrm{KDR}^{+} / \mathrm{CD} 34^{+}$and $\mathrm{KDR}^{+} / \mathrm{CD}_{133^{+}}$) were counted in peripheral blood using flow cytometry. In ex vivo expanded EPCs, the function was determined as chemotaxis to VEGF, proliferation, and survival. Results We observed thicker IMT in older as compared to younger subjects $(0.68 \pm 0.03 \mathrm{~mm}$ Vs. $0.48 \pm 0.02 \mathrm{~mm}, P<0.001)$. Importantly, there were significant inverse univariate correlations between IMT, EPC chemotaxis, and survival $(r=-0.466 P<0.05 ; r=-0.463, P<0.01)$. No correlation was observed with numbers of circulating EPCs. Multivariate regression analysis revealed that age, mean arterial pressure and migration of EPCs were independent predictors of IMT $\left(R^{2}=0.58\right)$. Conclusion Impaired EPC function may lead to accelerated vascular remodeling due to chronic impairment of endothelial maintenance.

Key words aging - Intima-media thickness endothelial progenitor cells

\section{Introduction}

The functional integrity of the vascular endothelium is essential to protect against the development of atherosclerosis. Disturbances in endothelial functions are associated with the loss of anti-adhesive and antiproliferative properties of the vessel wall, vascular inflammation, and vasoconstriction in the short term, and lead to structural changes and the development of atherosclerotic lesions when present chronically [10]. Early structural changes of the vascular wall can be determined non-invasively by measuring intimamedia thickness (IMT) in the common carotid artery (CCA) using high resolution ultrasound [4].

Successful endothelial regeneration is crucial for the prevention of atherosclerotic lesion formation. Until recently, it was thought that endothelial repair 
mechanisms constitute mainly of proliferation and migration of mature endothelial cells. More recent studies have shown that bone marrow-derived endothelial progenitor cells (EPCs) contribute to the regeneration and maintenance of endothelium [1]. EPCs have the ability to home to sites of ischemia or endothelial injury and differentiate to mature endothelial cells. This has led to the successful therapeutic use of EPC and different types of circulating progenitor cells in cardiovascular diseases in animal models [8, 11] and human studies [2, 8]. Studies have shown that the presence of cardiovascular risk factors results in a reduced number of circulating EPC and/or an impaired progenitor cell function $[5,7,13]$. In patients with coronary artery disease, a low number of circulating EPC has been shown to predict an increased risk to experience cardiovascular events [14].

Aging is associated with functional and structural changes of the vascular wall. Concerning the role of vascular progenitors in the development of atherosclerotic lesions, Rauscher et al. have demonstrated that treatment of atherosclerosis prone ApoE-deficient mice with bone marrow-derived progenitor cells from young animals prevented atherosclerosis progression, whereas the treatment with progenitor cells from aged animals was not effective [9]. We and others have previously shown that a reduced number or functional impairment of EPC contributes to the age-related endothelial vasomotor dysfunction $[6,7]$. Werner et al. have shown that the number of EPC predicts severe coronary endothelial dysfunction independent of classical cardiovascular risk factors including age [15]. The aim of the presented study was the investigation whether the number of circulating EPCs or the function of ex vivo expanded EPCs contributes to the age-related process of structural vessel wall remodeling. Therefore, we analyzed CCA IMT as a marker of early arteriosclerosis in the group of old and young healthy subjects without hypertension, hypercholesterolemia, diabetes, and smoking.

\section{Materials and methods}

We studied 20 young ( $25 \pm 1$ year) and 20 old (61 \pm 2 years) healthy subjects without hypertension, hypercholesterolemia, diabetes, and smoking as reported previously [6]. IMT was measured non-invasively at $1 \mathrm{~cm}$ proximal to the carotid bifurcation by high-resolution ultrasound. The number of circulating EPC was determined by flow cytometry as CD34/ KDR and CD133/KDR positive cells. Repeated FACS measurements (CD34/KDR) on identical samples showed an intraindividual coefficient of variation of
Table 1 Characteristics of the study population

\begin{tabular}{llll}
\hline Characteristics & $\begin{array}{l}\text { Young subjects } \\
(n=20)\end{array}$ & $\begin{array}{l}\text { Old subjects } \\
(n=20)\end{array}$ & $P$ value \\
\hline Age (years) & $25 \pm 0.6$ & $61 \pm 1.5$ & $<0.001$ \\
Men & $10(50 \%)$ & $7(35 \%)$ & \\
Body mass index $\left(\mathrm{kg} / \mathrm{m}^{2}\right)$ & $22 \pm 0.5$ & $24 \pm 2.4$ & $\mathrm{NS}$ \\
Systolic blood pressure $(\mathrm{mmHg})$ & $117 \pm 1.5$ & $122 \pm 2.7$ & $\mathrm{NS}$ \\
Diastolic blood pressure $(\mathrm{mmHg})$ & $77 \pm 1.5$ & $81 \pm 1.5$ & $\mathrm{NS}$ \\
Total cholesterol $(\mathrm{mg} / \mathrm{dL})$ & $190 \pm 5.6$ & $220 \pm 5.8$ & $<0.001$ \\
HDL cholesterol $(\mathrm{mg} / \mathrm{dL})$ & $70 \pm 3.7$ & $72 \pm 3.6$ & $\mathrm{NS}$ \\
LDL cholesterol $(\mathrm{mg} / \mathrm{dL})$ & $133 \pm 5.2$ & $142 \pm 6.0$ & $\mathrm{NS}$ \\
Triglycerides $(\mathrm{mg} / \mathrm{dL})$ & $87 \pm 9.7$ & $97 \pm 8.3$ & $\mathrm{NS}$ \\
Plasma glucose $(\mathrm{mg} / \mathrm{dL})$ & $88 \pm 1.6$ & $91 \pm 2.3$ & $\mathrm{NS}$ \\
C-reactive protein $(\mathrm{mg} / \mathrm{dL})$ & $0.05 \pm 0.03$ & $0.15 \pm 0.08$ & $\mathrm{NS}$ \\
\hline
\end{tabular}

$10 \%$ within-day and $22 \%$ day-to-day. This translates into a minimally detectable difference of 67-113 cells/ ml blood, respectively $(P<0.05$, power $>0.8)$.

Functional characteristics were assessed after cell culture enrichment of EPC by migration, proliferation, and EPC survival. Migratory capacity towards VEGF was determined using a modified Boyden chamber and proliferation was measured by a colorimetric assay based on the cleavage of tetrazolium salts by mitochondrial dehydrogenase. For testing EPC survival, mononuclear cells from peripheral blood were cultured for 4 days and adherent cells of endothelial lineage were microscopically identified by Ulex europaeus-agglutinin I-binding and acetylated LDL-uptake. In some cases, blood samples provided not enough cells to perform all culture assays. Results are expressed as means \pm standard error (SE). Comparisons between groups were analyzed by the unpaired Student $t$ test. Univariate correlations were calculated using Pearson's coefficient. To estimate the predictive value of EPC function in explaining variability of vascular structure measured by IMT, a multivariate linear regression analysis was performed. Statistical significance was assumed at $P<0.05$. All analyses were performed with SPSS 14.0.1 (SPSS Inc., Chicago, IL).

\section{Results}

The clinical characteristics are presented in Table 1. The IMT was significantly increased in old subjects as compared to young subjects $(0.68 \pm 0.03$ Vs. $0.48 \pm 0.02 \mathrm{~mm}, P<0.001)$. As described [6], the number of circulating EPC determined as CD34/KDR and CD133/KDR double positive cells was not different between groups, $\left(\mathrm{CD} 34 / \mathrm{KDR}^{+}: 436 \pm 88\right.$ Vs. $502 \pm 88$ cells $/ \mathrm{mL} ; P=0.590 ; \mathrm{CD} 133 / \mathrm{KDR}^{+}: 373 \pm 52$ Vs. $391 \pm 68$ cells $/ \mathrm{mL} ; P=0.846$ ). After ex vivo expansion, almost all (>95\%) adherent cells were 

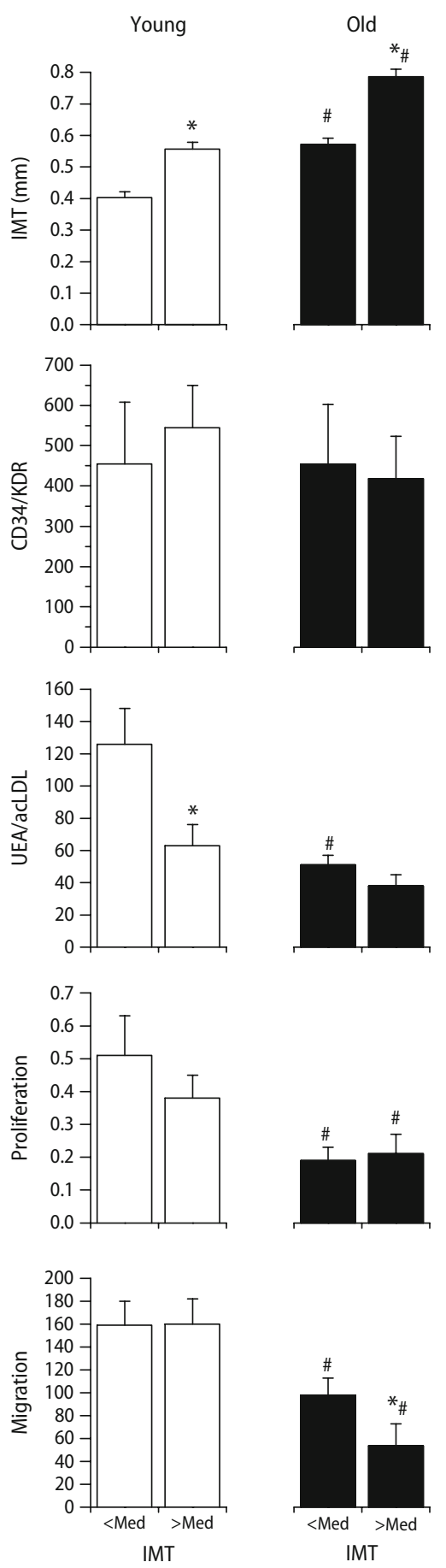

Fig. 1 EPC characteristics in young and old subjects stratified by intima-media thickness (IMT). Young and old subjects were dichotomized by their IMT and EPC characteristics were analyzed between age groups and within comparing age-matched groups with different IMT (Med = Median). Whereas EPC numbers remained similar in all groups, this revealed heterogenous differences in EPC functions with significantly decreased in EPC survival in young individuals with thicker IMT and impaired EPC migration in old individuals with thicker IMT as compared to the age-matched group with thinner IMT. ${ }^{*} P<0.05$ Vs. age-matched group, $\# P<0.05 \mathrm{Vs}$. respective young group
Table 2 Multivariate linear regression analysis

\begin{tabular}{lcc}
\hline & Standardized coefficient & $P$ value \\
\hline Age & 0.451 & 0.049 \\
Mean arterial pressure & 0.445 & 0.023 \\
Total cholesterol & -0.205 & 0.312 \\
EPC number (CD34 $\left./ \mathrm{KDR}^{+}\right)$ & -0.349 & 0.063 \\
EPC survival & -0.407 & 0.051 \\
EPC migration & -0.433 & 0.043 \\
EPC proliferation & 0.006 & 0.936 \\
Adjusted $R^{2}$ & 0.576 & 0.003 \\
ANOVA & & \\
\hline
\end{tabular}

positive for UEA-1 and acLDL uptake confirming the endothelial phenotype of these cells. The proliferative activity $(0.20 \pm 0.04$ Vs. $0.44 \pm 0.07$ a.u., $P=0.013)$ and chemotactic migration $(80 \pm 12$ Vs. $157 \pm 16$ cells $/ \mathrm{mm}^{2}, P<0.001$ ) of ex vivo expanded EPCs was reduced in old subjects as compared to young subjects. Furthermore, EPC survival (absolute number of UEA-1/acLDL positive cells) was lower in old compared to young subjects ( $45 \pm 5$ Vs. $93 \pm 14$ cells/ $\left.\mathrm{mm}^{2} ; P=0.003\right)$.

To further analyze the association between vascular remodeling and EPC features, we dichotomized the study groups based on IMT leading to young and old age-matched groups with IMT greater and smaller than the median, respectively (young: $0.40 \pm 0.02$ and $0.56 \pm 0.02 \mathrm{~mm}$; older: $0.57 \pm 0.02$ and $0.79 \pm$ $0.02 \mathrm{~mm}$, each $P<0.01$ ) [3]. This revealed that EPC survival in culture determined as adherent acLDL/ UEA positive cells was decreased in young individuals with thicker IMT $(126 \pm 22$ Vs. $63 \pm 13, P=0.002)$. EPC migration was not different between young subjects with different IMT $(159 \pm 21$ Vs. $160 \pm 22$ cells $\left./ \mathrm{mm}^{2}, P=0.976\right)$. In older subjects, EPC migration was lower in the group with thicker IMT (98 \pm 15 Vs. $54 \pm 19$ cells $\left./ \mathrm{mm}^{2}, P=0.011\right)$. The number of circulating EPCs as measured by CD34/KDR or CD133/KDR positive cells remained similar between the groups (Fig. 1).

Univariate regression analysis revealed a significant inverse correlation between IMT and both migratory capacity and EPC survival $(n=28$, $r=-0.466, P=0.012 ; n=36, r=-0.463, P=0.004)$ but not the proliferative activity $(n=27, r=-0.281$; $P=0.156)$. Furthermore, IMT correlated with age, mean arterial pressure (MAP) and total cholesterol. A multivariate linear regression analysis including age, MAP, total cholesterol, circulating EPC number, and functions of ex vivo expanded EPCs showed that age, MAP and EPC migration were independent predictors for IMT accounting for $58 \%$ of the total variability of IMT (adjusted $R^{2}=0.576, P<0.003$; Table 2). 


\section{Discussion}

The results of the present study show for the first time an age-dependent inverse relationship of EPC function ex vivo, but not EPC number in circulating blood, with manifest early arteriosclerotic vessel wall remodeling in subjects without hypertension, hypercholesterolemia, diabetes, and smoking.

Only a few studies have investigated the effect of EPCs, putative key players in vascular repair and maintenance, on age-dependent early atherosclerosis. Fadini et al. have shown that lower numbers of circulating $\mathrm{CD} 34^{+} / \mathrm{KDR}^{+}$EPCs were associated with thicker IMT in a middle aged group of subjects with a broad spectrum of cardiovascular risk and age-profile [3]. In the present paper, no differences in $\mathrm{CD} 34^{+}$/ $\mathrm{KDR}^{+}$and $\mathrm{CD} 133^{+} / \mathrm{KDR}^{+}$EPCs was seen between old and young subjects or between age-matched groups with different IMT whereby the EPC number was within the range described by Werner et al. [14]. The discrepancy with our present results may be explained by the fact that we have focused on aging as a sole cardiovascular risk factor and meticulously excluded hypertension, hypercholesterolemia, diabetes, and smoking as these factors were shown to be associated with decreased numbers of circulating EPCs. Other papers reporting an inverse association between age and EPC numbers have not excluded cardiovascular risk factors [12, 13]. Corroborating results by Xiao et al. we have also observed an age-dependently decreased EPC survival during culture as determined by acLDL-uptake and UEA binding. This may be explained by an age-dependent decline in functional properties of EPCs including adhesion, differentiation, and/or proliferation as observed in culture. Despite the small $\mathrm{n}$-value, our data show a robust statistically significant association between age and EPC migration, but not EPC numbers in blood suggesting that the age-dependent functional impairment of EPCs is more pronounced than quantitative changes. Furthermore, our data suggest that this may be a step wise process as impaired EPC proliferation was present even early in life and was associated with early arteriosclerotic remodeling independent of similar EPC numbers in circulating blood. In older subjects with already decreased proliferation and survival an impaired EPC migration became a dominant determinant of vessel wall remodeling.

One limitation of this study and other important studies in the field is that the number of cells in peripheral blood is compared to the function of ex vivo expanded EPCs representing a different subgroup of EPCs that have differentiated ex vivo to a more mature endothelial phenotype $[3,6,13]$. Asahara et al. have previously shown that ex vivo expanded EPCs are derived from blood $\mathrm{CD} 34^{+}$and $\mathrm{KDR}^{+}$EPCs [1]. The function of ex vivo expanded EPCs is of potential clinical importance as the migratory capacity was an independent determinant of the clinical outcome when these cells were used as a cell based therapy after myocardial infarction [2].

Taken together, our data suggest that EPC function is not only necessary for the maintenance of vascular function but also for vascular structure. Our current data lend further evidence to the upcoming paradigm that EPCs represent an integral part in the cellular repair mechanisms for endothelial regeneration and maintenance. Clinically, these results imply that EPC dysfunction may be an important factor in the development of age-related arteriosclerotic disease and a potential biomarker for vascular lesions and future adverse events.

\section{References}

1. Asahara T, Masuda H, Takahashi T, Kalka C, Pastore C, Silver M, Kearne M, Magner M, Isner JM (1999) Bone marrow origin of endothelial progenitor cells responsible for postnatal vasculogenesis in physiological and pathological neovascularization. Circ Res $85: 221-228$

2. Assmus B, Schaechinger V, Teupe C, Britten M, Lehmann R, Doebert N, Gruenwald F, Aicher A, Urbich C, Martin H, Hoelzer D, Dimmeler S, Zeiher AM (2002) Transplantation of Progenitor Cells and Regeneration Enhancement in Acute Myocardial Intarction (TOPCARE-AMI). Circulation 106:3009-3017
3. Fadini GP, Coracina A, Baesso I, Agostini C, Tiengo A, Avogaro A (2006) Peripheral blood CD34+KDR+ endothelial progenitor cells are determinants of subclinical atherosclerosis in a middle-aged general population. Stroke 37:2277-2282

4. Grobbee DE, Bots ML (1994) Carotid artery intima-media thickness as an indicator of generalized atherosclerosis. J Intern Med 236:567-573

5. Heiss C, Amabile N, Lee AC, May Real W, Schick SF, Lao D, Wong ML, Jahn S, Angeli FS, Minasi P, Springer ML, Hammond SK, Glantz SA, Grossman W, Balmes JR, Yeghiazarians Y (2008) Brief secondhand smoke exposure depresses endothelial progenitor cells activity and endothelial function. J Am Coll Cardiol 51:1760-1771
6. Heiss C, Keymel S, Niesler U, Ziemann J, Kelm M, Kalka C (2005) Impaired progenitor cell activity in age-related endothelial dysfunction. J Am Coll Cardiol 45:1441-1448

7. Hill JM, Zalos G, Halcox JPJ, Schenke WH, Waclawiw MA, Quyyumi AA, Finkel T (2003) Circulating endothelial progenitor cells, vascular function, and cardiovascular risk. $\mathrm{N}$ Engl J Med 348:593-600

8. Lyngbaek S, Schneider M, Hansen JL, Sheikh SP (2007) Cardiac regeneration by resident stem and progenitor cells in the adult heart. Basic Res Cardiol 102:101-114 
9. Rauscher FM, Goldschmidt-Clermont PJ, Davis BH, Wang T, Gregg D, Ramaswami P, Pippen AM, Annex $\mathrm{BH}$, Dong C, Taylor DA (2003) Aging, progenitor cell exhaustion, and atherosclerosis. Circulation 108:457-463

10. Ross R (1986) The pathogenesis of atherosclerosis-an update. $\mathrm{N}$ Engl J Med 314:488-500

11. Schuh A, Liehn E, Sasse A, Hristov M, Sobota R, Kelm M, Merx M, Weber C (2007) Transplantation of endothelial progenitor cells improves neovascularization and left ventricular function after myocardial infarction in a rat model. Basic Res Cardiol 103:69-77
12. Thum T, Hoeber S, Froese S, Klink I, Stichtenoth DO, Galuppo P, Jakob M, Tsikas D, Anker SD, Poole-Wilson PA, Borlak J, Ertl G, Bauersachs J (2007) Age-dependent impairment of endothelial progenitor cells is corrected by growth-hormone-mediated increase of insulin-like growth-factor-1. Circ Res 100:434-443

13. Vasa M, Fichtlscherer S, Aicher A, Adler K, Urbich C, Martin $\mathrm{H}$, Zeiher AM, Dimmeler S (2001) Number and migratory activity of circulating endothelial progenitor cells inversely correlate with risk factors for coronary artery disease. Circ Res 89:e1-e7
14. Werner N, Kosiol S, Schiegl T, Ahlers $\mathrm{P}$, Walenta $\mathrm{K}$, Link A, Bohm M, Nickenig G (2005) Circulating endothelial progenitor cells and cardiovascular outcomes. N Engl J Med 353:999-1007

15. Werner N, Wassmann S, Ahlers P, Schiegl T, Kosiol S, Link A, Walenta K, Nickenig G (2007) Endothelial progenitor cells correlate with endothelial function in patients with coronary artery disease. Basic Res Cardiol 102:565571 